\title{
Testosterone Levels Do Not Decline with Age in Healthy Men
}

\author{
Akanksha Mehta ${ }^{1 *}$, Alexander Bolyakov ${ }^{1}$, Raymond C. Sultan ${ }^{1}$, Laurent Vaucher ${ }^{2}$, \\ Anna Mielnik ${ }^{1}$, Joseph Kiper ${ }^{1}$, Darius A. Paduch ${ }^{1}$ \\ ${ }^{1}$ Department of Urology, Weill Cornell Medical College, New York, USA \\ ${ }^{2}$ Department of Urology, Centre Hospitalier Universitaire Vaudois, Lausanne, Switzerland \\ Email:*akm9009@med.cornell.edu
}

Received June 3, 2013; revised July 1, 2013; accepted July 9, 2013

Copyright (C) 2013 Akanksha Mehta et al. This is an open access article distributed under the Creative Commons Attribution License, which permits unrestricted use, distribution, and reproduction in any medium, provided the original work is properly cited.

\begin{abstract}
Aim: To establish norms for reproductive hormones in healthy males with normal urologic and sexual function, and to assess the change in reproductive hormone levels with respect to age among healthy males. Methods: Healthy volunteers aged 18 - 29 (group 1) and 45 - 65 (group 2) were recruited for enrollment in a prospective study. Inclusion criteria comprised normal urinary, ejaculatory, orgasmic, and erectile function, as determined by IPSS, MSHQ, and IEFF-15. Men with history of chronic medical illnesses or chronic medication use were excluded. Fifty men met the study criteria. Each participant underwent physical examination and standardized serum hormone evaluation using ELISA and EIA methods. Statistical analysis was performed using JMP 8.0 software (SAS Institute Inc., Cary, NC), to compare hormone levels between the two groups of men. Results: There were 25 men each in groups 1 (mean age 26) and 2 (mean age 51). Overall, 46\% were Caucasian, 31\% African American, $15 \%$ Hispanic, and $8 \%$ Asian. There was no statistically significant difference in serum total T, SHBG, E2, or LH between groups 1 and 2. Notably, the 95\% CI for serum T levels for both groups of men were considerably higher than commonly accepted lower-end cut-off limits. Conclusion: Serum $\mathrm{T}$ levels do not vary significantly with age, in otherwise healthy men with normal sexual and urologic function. Furthermore, healthy men have much higher serum total and free $\mathrm{T}$ levels than the lower-end reference limits provided by commercial laboratories.
\end{abstract}

Keywords: Testosterone; Aging; Hypogonadism; Reference Values

\section{Introduction}

Hypogonadism is a clinical condition characterized by low levels of serum testosterone (T), in association with specific signs and symptoms of low $\mathrm{T}$, which may include physical, sexual, reproductive, and cognitive effects. Hypogonadism affects an estimated two to four million men in the United States; its prevalence increases with age [1]. When hypogonadism occurs in older men, the condition is often called andropause, or androgen deficiency of the aging male [2].

Testosterone supplementation for the treatment of hypogonadism has increased substantially in the United States over the past few years, with an increase of more than $500 \%$ in prescription sales of testosterone products since 1993 [3]. Testosterone replacement therapy (TRT) results in a demonstrable improvement in symptoms of hypogonadism, including diminished libido, energy and

${ }^{*}$ Corresponding author. well-being, impaired cognition, decreased muscle mass/ strength, anemia, osteoporosis, erectile dysfunction, and visceral obesity [4-13].

Because the diagnosis of hypogonadism requires laboratory confirmation of a low level of testosterone, clinicians rely heavily on laboratory reference ranges to determine whether a patient may be a candidate for TRT. However, at present there is no universally accepted definition of hypogonadism, no universally used assay for the analysis of serum $\mathrm{T}$, and no universally agreed-upon indications for the initiation and use of TRT.

Guidelines from the Endocrine Society maintain that $\mathrm{T}$ levels below $300 \mathrm{ng} / \mathrm{dL}$ are diagnostic of hypogonadism, while higher levels are normal [14]. Accordingly, the Society only recommends TRT in men with unequivocally low testosterone concentrations and symptoms associated with androgen deficiency [14]. Meanwhile, a consensus statement from the ISA, ISSAM, EAU, EAA, and ASA recommends that $\mathrm{T}$ levels above $350 \mathrm{ng} / \mathrm{dL}$ do 
not require treatment, while levels below $230 \mathrm{ng} / \mathrm{dL}$ do [15]. Yet other authorities emphasize the importance of the symptoms of androgen deficiency over serum biochemistry, suggesting that men may be "hypogonadal" at the tissue level while having a normal T level $[16,17]$.

The confusion stems, in part, from the variability in testosterone assays and their interpretation. Historically, the reference range for serum testosterone reported by scientific publications was based on traditional radio-immunoassay (RIA) methods, and ranged from $300-1000$ $\mathrm{ng} / \mathrm{dl}$ (10.4 - $34.7 \mathrm{nmol} /$ liter) [18]. Over the last decade, techniques for testosterone measurement have evolved from RIA, to automated enzyme-linked immunoassays (EIA) available in most laboratories, and liquid chromatography-mass spectroscopy methods in reference laboratories. As a result, widely variable reference ranges have been reported for different assays, spanning lowend clinical detection limits of $170-200 \mathrm{ng} / \mathrm{dL}$ to upper-end limits of $700-800 \mathrm{ng} / \mathrm{dL}$ [18]. However, these reference ranges are not specific for healthy men with normal sexual and reproductive function, and are rarely adequately adjusted for age $[19,20]$. Consequently, an objective comparison of results from different published studies, using different assays, is fraught with error.

The objective of this study was two-fold. Firstly, we aimed to establish norms for reproductive hormones based on a diverse population of healthy males with normal urologic and sexual function. Secondly, we aimed to assess the change in reproductive hormone levels with respect to age, in a cross sectional analysis of healthy men from two different age groups.

\section{Materials and Methods}

\subsection{Study Population}

Two groups of healthy male volunteers were recruited for enrollment into this prospective study via informational study flyers distributed amongst New York Presbyterian Hospital-affiliated medical facilities, and advertisements in local newspapers. Group 1, the younger group, consisted of men between the ages of 18 - 29 years, while group 2, the older group, consisted of men aged 45 - 65 years. All individuals who expressed interest in the study were pre-screened by the study coordinator (JK). Individuals with any history of a chronic medical condition or chronic medication use were excluded. Others were invited for enrollment on a first-come first-served basis.

Following pre-screening, all eligible volunteers completed the International Prostate Symptom Score (IPSS), International Index of Erectile Dysfunction (IIEF-15), and Male Sexual Health Questionnaire (MSHQ). All volunteers also underwent a complete physical examination by an attending physician (DAP). Only men with a normal physical exam, and normal erectile, ejaculatory, orgasmic, and voiding function, were included in the study. A total of 50 men were enrolled into the study, divided equally between groups 1 and 2 . All study participants were provided a modest inconvenience fee.

Approval for this study was provided by the Weill Cornell Medical College Institutional Review Board.

\subsection{Measurement of Hormone Levels}

All subjects were scheduled for baseline hormone evaluation between the hours of 7 and 10 a.m. A peripheral blood sample was obtained from each study participant $(25 \mathrm{~mL})$, centrifuged for 30 minutes, and the serum transferred to a collection tube. All samples were maintained at $-20^{\circ} \mathrm{C}$ prior to completion of hormonal assays, following which samples were transferred to $-80^{\circ} \mathrm{C}$. The hormones measured included: total testosterone (tT), free testosterone (fT), sex-hormone binding globulin (SHBG), estradiol (E2), follicle stimulating hormone (FSH), luteinizing hormone (LH), dehydroepiandrosterone (DHEA) and dehydroepiandrosterone sulfate (DHEA-S). All hormones were measured in duplicate, on the day of collection, by the same technician (AB), using commercially available enzyme-linked immunosorbent assays (ELISA) and enzyme immunoassays (EIA).

For each assay, micro plates were read using SpectraMax 340 PC micro-plate spectrophotometer, controlled by Soft Max Pro data analysis software (Molecular Devices, Sunnyvale, CA), and concentrations calculated using four-parameter curve fit. Absorbance was measured at $450 \mathrm{~nm}$, and dual wavelength correction at 620 $\mathrm{nm}$ was used in all assays. Standards and controls provided by manufacturer were included with each run and on each plate.

Biorad Lyphochek Assayed Chemistry Control Bilevel packs (Bio-Rad Laboratories, Hercules, CA) were used for quality control of assays. All measures were performed in duplicates. Samples with results exceeding dynamic range were diluted using charcoal stripped steroids free serum, and re-analyzed. In order to calculate inter-assay variability, ten randomly-selected subjects from each group underwent repeat hormone evaluation per the study protocol, within 6 months of the initiation of the study.

\subsection{Statistical Analysis}

All patients in group 1 completed the study. Three patients from group 2, aged 56, 57, and 59 years, were unable to complete the study, and were excluded from the final analysis. All results were entered in a study specific database and analyzed using JMP 8.0 statistical software (SAS Institute Inc., Cary, NC), to compare the various hormone levels between the two groups of men using 
Student's t-test. A p-value $<0.05$ was considered statistically significant. GraphPad Prism 5.0 (GraphPad Software Inc., La Jolla, CA) was used to test for normal distribution of hormonal results and to verify the calculated hormone concentrations obtained from SoftMax Pro (Molecular Devices, Sunnyvale, CA).

\section{Results}

Twenty-five men each were enrolled into group 1 (mean age: 26) and group 2 (mean age 51). Demographic data was available for 48 subjects. Overall, 46\% (22/48) of men were Caucasian, 31\% (15/48) African American, 15\% (7/48) Hispanic, and 8\% (4/48) Asian. Ninety-five percent of study subjects identified themselves as being heterosexual.

Details of the manufacturers, catalog numbers, reported reference ranges, minimum and maximum limits of detection, and inter-assay variability for each of the hormone assays used in this study is summarized in Table 1 . The laboratory co-efficient of variance was $\leq 6.2 \%$ for each assay, indicating good reproducibility with limited inter-assay variability.

Serum hormone levels of tT, fT, SHBG, E2, FSH, and LH, DHEA, and DHEA-S in the two groups of men are listed in Table 2. There was no statistically significant difference noted in serum tT (766 vs. $599 \mathrm{ng} / \mathrm{dL}$ ), SHBG (25.1 vs. $32.5 \mathrm{nmol} / \mathrm{L})$, E2 (17.1 vs. $22.7 \mathrm{pg} / \mathrm{mL}$ ), or $\mathrm{LH}$ (5.37 vs. $7.56 \mathrm{mIU} / \mathrm{mL}$ ) between groups 1 and 2, respectively. Men in group 1 had higher levels of serum fT (74.5 vs. $50.9 \mathrm{pg} / \mathrm{mL}, \mathrm{p}=0.004)$, DHEA (11.4 vs. 7.58 $\mathrm{ng} / \mathrm{mL}, \mathrm{p}=0.04)$, and DHEA-S (2.84 vs. $1.35 \mathrm{ug} / \mathrm{mL}, \mathrm{p}$ $<0.001)$, compared to the older cohort of men in group 2 . Serum FSH levels were lower in group 1 compared to group 2 (1.97 vs. $5.00 \mathrm{mIU} / \mathrm{L}, \mathrm{p}<0.001)$.

Compared to manufacturer-provided reference ranges (Table 1), the 95\% CI values for serum $\mathrm{tT}$, fT, DHEA, and DHEA-S were higher among the study subjects in both groups 1 and 2 (Table 2). Interestingly, the 95\% CI range for serum FSH was both lower and tighter among the study subjects, who represent healthy men, than the reference ranges that have traditionally been reported by manufacturers.

\section{Discussion}

Our results demonstrate that serum testosterone levels are not significantly different in healthy men between the second and sixth decades of life. Furthermore, the range of distribution of serum testosterone levels in the study subjects was considerably higher than what is commonly reported by manufactures of commercially available testosterone assays, indicating that reference ranges for healthy men with normal sexual and urologic function may be different than the references ranges for the gen- eral population of men. These findings are in contrast to recent reports from longitudinal studies of aging men, which show that serum testosterone levels decline with each decade of life [21-23]. However, these population-based studies included men over the age of 65 , and did not specifically select for healthy men without any medical comorbidities.

To our knowledge, to date, serum reference ranges of reproductive hormones have not been studied in a diverse population of healthy men with documented normal urologic and sexual function. The evaluation of orgasmic and ejaculatory function in healthy men with normal sexual function is difficult because of the ethical issues involved, concerns for privacy and confidentiality, increased scrutiny by internal review boards towards studies of human sexuality, and complex logistical issues involved in screening and enrolling patients for such studies. Furthermore, studies of healthy subjects are expensive, and difficult to obtain funding for, as no clinical benefit of "pharmacological" treatment can be proven in studies of normal subjects. Nevertheless, the importance of such studies, to establish a baseline reference range, cannot be emphasized enough.

Assays for the measurement of serum testosterone have been criticized for their unreliability [24,25], and variable limits of detection. Taieb et al. compared testosterone levels for 116 samples (50 males, 55 females and 11 children) measured by 10 different commercial kits with results obtained by isotope dilution-mass spectrometry, and concluded that none of the immunoassays tested was sufficiently reliable for the investigation of sera from children and women, in whom very low testosterone concentrations are expected [26]. There are significant intra-individual fluctuations in serum testosterone levels, and a wide range of testosterone levels in the general male population. Thus, it is likely that the variability between assays derives in large part from failure to establish specific norms for a healthy, young to middle-aged population of men. Additionally, many manufacturer-reported references ranges assume the serum testosterone follows a normal distribution, which is not, in fact, the case. As a result, manufacturer-quoted reference ranges are often too low, making them less sensitive in detecting hypogonadism [27]. This assertion is certainly supported by our data, which demonstrates a higher range of distribution of serum testosterone levels in the study subjects, compared to published reference ranges (Table 1).

While several cross sectional studies have demonstrated lower concentrations of circulating total and/or free $\mathrm{T}$ in older men [28-37], other have shown that $\mathrm{T}$ levels do not fall significantly with age in exceptionally healthy men $[38,39]$, questioning the relative roles of age-related illness versus aging per se in producing the 
Table 1. Manufacturer reported reference ranges, limits of detection, and laboratory co-efficient of variance for the assays used.

\begin{tabular}{|c|c|c|c|c|c|c|}
\hline Hormone & Type of Assay & Manufacturer & Catalog No. & $\begin{array}{l}\text { Manufacturer Reported } \\
\text { Reference Range }\end{array}$ & $\begin{array}{l}\text { Limits of } \\
\text { Detection }\end{array}$ & $\begin{array}{l}\text { Lab Co-efficient } \\
\text { of Variance (\%) }\end{array}$ \\
\hline $\mathrm{T}$ & EIA & $\begin{array}{l}\text { Beckman Coulter; } \\
\text { Webster, TX }\end{array}$ & DSL-10-4000 & $\begin{array}{l}290-990 \mathrm{ng} / \mathrm{dL}(20-30 \mathrm{yr} \text { old }) \\
160-660 \mathrm{ng} / \mathrm{dL}(50-60 \mathrm{yr} \text { old })\end{array}$ & $100-2500 \mathrm{ng} / \mathrm{dL}$ & 6.2 \\
\hline Free $\mathrm{T}$ & EIA & $\begin{array}{l}\text { Beckman Coulter; } \\
\text { Webster, TX }\end{array}$ & DSL-10-49100 & $6.2-28.1 \mathrm{pg} / \mathrm{mL}$ & $0.25-100 \mathrm{pg} / \mathrm{mL}$ & 1.9 \\
\hline LH & ELISA & $\begin{array}{l}\text { Beckman Coulter; } \\
\text { Webster, TX }\end{array}$ & DSL-10-4600 & $1.08-8.34 \mathrm{mIU} / \mathrm{mL}$ & $1-100 \mathrm{mIU} / \mathrm{mL}$ & 3.5 \\
\hline FSH & EIA & ALPCO; Salem, NH & 11-FSHHU-E01 & $1.0-18.0 \mathrm{mIU} / \mathrm{mL}$ & $5-100 \mathrm{mIU} / \mathrm{mL}$ & 2.8 \\
\hline SHBG & EIA & ALPCO; Salem, NH & 11-SHBHU-E01 & $7.0-70.0 \mathrm{nmol} / \mathrm{L}$ & $3.3-295 \mathrm{nmol} / \mathrm{L}$ & 5.1 \\
\hline E2 & EIA & ALPCO; Salem, NH & 20-DR-4399 & $10.0-36.0 \mathrm{pg} / \mathrm{mL}$ & $3-200 \mathrm{pg} / \mathrm{mL}$ & 2.8 \\
\hline DHEA & EIA & $\begin{array}{l}\text { Beckman Coulter; } \\
\text { Webster, TX }\end{array}$ & DSL-10-9000 & $1.8-12.5 \mathrm{ng} / \mathrm{mL}$ & $0.2-27 \mathrm{ng} / \mathrm{mL}$ & 1.7 \\
\hline DHEA-S & EIA & ALPCO; Salem, NH & 11-DHEHU-E01 & $0.39-4.63 \mathrm{ug} / \mathrm{mL}$ & $0.005-10 \mathrm{ug} / \mathrm{mL}$ & 2.9 \\
\hline
\end{tabular}

EIA = Enzyme immunoassay; ELISA = Enzyme-linked immunosorbent assay; $\mathrm{T}=$ Testosterone; $\mathrm{LH}=$ Luteinizing hormone; FSH $=$ Follicle stimulating hormone; SHBG = Sex-hormone binding globulin; E2 = Estradiol; DHEA = Dehydroepiandrosterone; DHEA-S = Dehydroepiandrosterone sulfate.

Table 2. Means and distribution of serum hormone levels (reported as $95 \% \mathrm{CI}$ ) in healthy men of different age groups.

\begin{tabular}{cccc}
\hline & Group 1 (Age 18 - 29) & Group 2 (Age 45 - 65) & Statistical significance \\
\hline Total T $(95 \% \mathrm{CI})$ & $766(569-963) \mathrm{ng} / \mathrm{dL}$ & $599(497-700) \mathrm{ng} / \mathrm{dL}$ & $\mathrm{p}=0.11$ \\
Free T $(95 \% \mathrm{CI})$ & $74.5(60.6-88.4) \mathrm{pg} / \mathrm{mL}$ & $50.9(44.2-57.6) \mathrm{pg} / \mathrm{mL}$ & $\mathrm{p}=0.004$ \\
SHBG $(95 \% \mathrm{CI})$ & $25.1(15.8-34.4) \mathrm{nmol} / \mathrm{L}$ & $32.5(26.4-38.7) \mathrm{nmol} / \mathrm{L}$ & $\mathrm{p}=0.16$ \\
E2 $(95 \% \mathrm{CI})$ & $17.1(11.4-22.7) \mathrm{pg} / \mathrm{mL}$ & $22.7(9.67-35.8) \mathrm{pg} / \mathrm{mL}$ & $\mathrm{p}=0.42$ \\
FSH $(95 \% \mathrm{CI})$ & $1.97(1.32-2.61) \mathrm{mIU} / \mathrm{mL}$ & $5.00(3.67-6.34) \mathrm{mIU} / \mathrm{mL}$ & $\mathrm{p}<0.001$ \\
LH $(95 \% \mathrm{CI})$ & $5.37(2.62-8.13) \mathrm{mIU} / \mathrm{mL}$ & $7.56(3.42-11.7) \mathrm{mIU} / \mathrm{mL}$ & $\mathrm{p}=0.36$ \\
DHEA $(95 \% \mathrm{CI})$ & $11.4(7.97-14.8) \mathrm{ng} / \mathrm{mL}$ & $7.58(6.15-9.02) \mathrm{ng} / \mathrm{mL}$ & $\mathrm{p}=0.04$ \\
DHEA-S $(95 \% \mathrm{CI})$ & $2.84(2.26-3.42) \mathrm{ug} / \mathrm{mL}$ & $1.35(1.04-6.66) \mathrm{ug} / \mathrm{mL}$ & $\mathrm{p}<0.001$ \\
\hline
\end{tabular}

observed decreases in serum testosterone. In the present study, which strictly excluded study subjects on the basis of any history of chronic medical illness or medication use, no significant decrease in serum testosterone was noted with increasing age. The utility of age-adjusted norms for serum testosterone levels has long been debated in the literature $[27,40,41]$. However, the present data suggests that establishing norms based on healthy men may be more important and utile than using age adjusted norms.

Lazarou et al. [19] point out that if hypogonadism affects $15 \%-35 \%$ for men over the age of 50 years [1], but only $2.5 \%$ of values are categorized as "low," then a large majority of affected men will fail to be correctly identified as hypogonadal. Men who stand to benefit from TRT may not be offered treatment. The use of age-adjusted values may decrease the test sensitivity for detecting androgen deficiency in aging males [42]. While the use of age-adjusted norms may make sense for the statistical representation of a population, it has no clinical justification for the diagnosis of hypogonadism [19]. Our data lends supports the possibility that the use of norms based on healthy men with normal sexual function may optimize clinical care of both older and younger men.

One limitation of this study is the small sample size of healthy volunteers recruited for participation. Validation of our results in a larger and equally diverse population of healthy men would be beneficial. Secondly, the enrollment criteria did not specifically require documented paternity or other evidence of normal reproductive function, such as semen analyses. While normal reproductive function was assumed among the study subjects, based on a normal urologic, medical, and sexual history, confirmation of paternity or normal semen analysis would further strengthen the findings of this study. The gold standard assay for the measurement of serum testosterone is liquid chromatography-mass spectroscopy, used primarily in reference and research laboratories [43]. Nevertheless, for this study, we chose to use EIA and ELISA assays for the measurement of reproductive hormones in our study population, because these methods are commercially available and, therefore, more widely used in investigative laboratories.

In summary, healthy men with normal sexual function have much higher total and free testosterone levels, than the "normal" reference ranges commonly reported by 
commercial assays. In healthy men, with normal urologic and sexual function, serum testosterone levels do not appear to vary significantly with age. These findings are important for the diagnosis and treatment of hypogonadism in the general male population.

\section{REFERENCES}

[1] S. M. Harman, et al., "Longitudinal Effects of Aging on Serum Total and Free Testosterone Levels in Healthy Men. Baltimore Longitudinal Study of Aging," The Journal of Clinical Endocrinology \& Metabolism, Vol. 86, No. 2, 2001, pp. 724-731. doi:10.1210/jc.86.2.724

[2] E. L. Rhoden and A. Morgentaler, "Risks of Testosterone-Replacement Therapy and Recommendations for Monitoring," The New England Journal of Medicine, Vol. 350, No. 5, 2004, pp. 482-492. doi:10.1056/NEJMra022251

[3] S. Bhasin and J. G. Buckwalter, "Testosterone Supplementation in Older Men: A Rational Idea Whose Time Has not yet Come," Journal of Andrology, Vol. 22, No. 5, 2001, pp. 718-731.

[4] J. L. Tenover, "Male Hormone Replacement Therapy Including Andropause," Endocrinology and Metabolism Clinics of North America, Vol. 27, No. 4, 1998, pp. 969987. doi:10.1016/S0889-8529(05)70050-5

[5] P. P. J. Snyder, et al., "Effects of Testosterone Replacement in Hypogonadal Men," The Journal of Clinical Endocrinology \& Metabolism, Vol. 85, No. 8, 2000, pp. 2670-2677. doi: $10.1210 /$ jc.85.8.2670

[6] R. Sih, et al., "Testosterone Replacement in Older Hypogonadal Men: A 12-Month Randomized Controlled Trial," The Journal of Clinical Endocrinology \& Metabolism, Vol. 82, No. 6, 1997, pp. 1661-1667. doi:10.1210/jc.82.6.1661

[7] A. M. Kenny, et al., "Effects of Transdermal Testosterone on Bone and Muscle in Older Men with Low Bioavailable Testosterone Levels," The Journals of Gerontology Series A: Biological Sciences and Medical Sciences, Vol. 56, No. 5, 2001, pp. 266-272. doi:10.1093/gerona/56.5.M266

[8] A. S. Dobs, et al., Pharmacokinetics, Efficacy, and Safety of a Permeation-Enhanced Testosterone Transdermal System in Comparison with Bi-Weekly Injections of Testosterone Enanthate for the Treatment of Hypogonadal Men. The Journal of Clinical Endocrinology \& Metabolism, Vol. 84, No. 10, 1999, pp. 3469-3478. doi:10.1210/jc.84.10.3469

[9] P. P. J. Snyder, et al., "Effect of Testosterone Treatment on Bone Mineral Density in Men over 65 Years of Age," The Journal of Clinical Endocrinology \& Metabolism, Vol. 84, No. 6, 1999, pp. 1966-1972. doi:10.1210/jc.84.6.1966

[10] A. Morgentaler, "A 66-Year-Old Man with Sexual Dysfunction," Journal of the American Medical Association, Vol. 291, No. 24, 2004, pp. 2994-3003. doi:10.1001/jama.291.24.2994

[11] C. Steidle, et al., "AA2500 Testosterone Gel Normalizes
Androgen Levels in Aging Males with Improvements in Body Composition and Sexual Function," The Journal of Clinical Endocrinology \& Metabolism, Vol. 88, No. 6, 2003, pp. 2673-2681. doi:10.1210/jc.2002-021058

[12] M. C. Raynor, et al., "Androgen Deficiency in the Aging Male: A Guide to Diagnosis and Testosterone Replacement Therapy," The Canadian Journal of Urology, Vol. 14, Suppl. 1, 2007, pp. 63-68.

[13] R. Shabsigh, "Testosterone Therapy in Erectile Dysfunction and Hypogonadism," The Journal of Sexual Medicine, Vol. 2, No. 6, 2005, pp. 785-792. doi:10.1111/j.1743-6109.2005.00139.x

[14] S. Bhasin, et al., "Testosterone Therapy in Men with Androgen Deficiency Syndromes: An Endocrine Society Clinical Practice Guideline," The Journal of Clinical Endocrinology and Metabolism, Vol. 95, No. 6, 2010, pp. 2536-2559. doi:10.1210/jc.2009-2354

[15] C. Wang, et al., "Investigation, Treatment, and Monitoring of Late-Onset Hypogonadism in Males: ISA, ISSAM, EAU, EAA, and ASA Recommendations," European Urology, Vol. 55, No. 1, 2009, pp. 121-130. doi:10.1016/j.eururo.2008.08.033

[16] M. Carruthers, "The Paradox Dividing Testosterone Deficiency Symptoms and Androgen Assays: A Closer Look at the Cellular and Molecular Mechanisms of Androgen Action," The Journal of Sexual Medicine, Vol. 5, No. 4, 2008, pp. 998-1012. doi:10.1111/j.1743-6109.2007.00721.x

[17] J. Bain, G. Brock and I. Kuzmarov, "Canadian Society for the Study of the Aging Male: Response to Health Canada's Position Paper on Testosterone Treatment," The Journal of Sexual Medicine, Vol. 4, No. 3, 2007, pp. 558566. doi:10.1111/j.1743-6109.2007.00488.x

[18] C. Wang, et al., "Measurement of Total Serum Testosterone in Adult Men: Comparison of Current Laboratory Methods versus Liquid Chromatography-Tandem Mass Spectrometry," The Journal of Clinical Endocrinology \& Metabolism, Vol. 89, No. 2, 2004, pp. 534-543. doi:10.1210/jc.2003-031287

[19] S. Lazarou, L. Reyes-Vallejo and A. Morgentaler, "Wide Variability in Laboratory Reference Values for Serum Testosterone," The Journal of Sexual Medicine, Vol. 3, No. 6, 2006, pp. 1085-1089. doi:10.1111/j.1743-6109.2006.00334.x

[20] N. Friedrich, et al., "Reference Ranges for Serum Dehydroepiandrosterone Sulfate and Testosterone in Adult Men," Journal of Andrology, Vol. 29, No. 6, 2008, pp. 610-617. doi:10.2164/jandrol.108.005561

[21] H. A. Feldman, et al., "Age Trends in the Level of Serum Testosterone and Other Hormones in Middle-Aged Men: Longitudinal Results from the Massachusetts Male Aging Study," The Journal of Clinical Endocrinology and Metabolism, Vol. 87, No. 2, 2002, pp. 589-598. doi:10.1210/jc.87.2.589

[22] S. M. Harman, et al., "Longitudinal Effects of Aging on Serum Total and Free Testosterone Levels in Healthy Men. Baltimore Longitudinal Study of Aging," The Journal of Clinical Endocrinology and Metabolism, Vol. 86, No. 2, 2001, pp. 724-731. doi:10.1210/jc.86.2.724 
[23] F. C. Wu, et al., "Hypothalamic-Pituitary-Testicular Axis Disruptions in Older Men Are Differentially Linked to Age and Modifiable Risk Factors: The European Male Aging Study," The Journal of Clinical Endocrinology and Metabolism, Vol. 93, No. 7, 2008, pp. 2737-2745. doi: $10.1210 /$ jc. $2007-1972$

[24] A. M. Matsumoto and W. J. Bremner, "Serum Testosterone Assays-Accuracy Matters," The Journal of Clinical Endocrinology \& Metabolism, Vol. 89, No. 2, 2004, pp. 520-524. doi:10.1210/jc.2003-032175

[25] K. Sikaris, et al., "Reproductive Hormone Reference Intervals for Healthy Fertile Young Men: Evaluation of Automated Platform Assays," The Journal of Clinical Endocrinology \& Metabolism, Vol. 90, No. 11, 2005, pp. 5928-5936. doi:10.1210/jc.2005-0962

[26] J. Taieb, et al., "Testosterone Measured by 10 Immunoassays and by Isotope-Dilution Gas ChromatographyMass Spectrometry in Sera from 116 Men, Women, and Children," Clinical Chemistry, Vol. 49, No. 8, 2003, pp. 1381-1395. doi:10.1373/49.8.1381

[27] M. J. Wheeler and S. C. Barnes, "Measurement of Testosterone in the Diagnosis of Hypogonadism in the Ageing Male," Clinical Endocrinology, Vol. 69, No. 4, 2008, pp. 515-525. doi:10.1111/j.1365-2265.2008.03325.x

[28] A. Vermeulen, R. Rubens and L. Verdonck, "Testosterone Secretion and Metabolism in Male Senescence," The Journal of Clinical Endocrinology \& Metabolism, Vol. 34, No. 4, 1972, pp. 730-735. doi:10.1210/jcem-34-4-730

[29] R. Rubens, M. Dhont and A. Vermeulen, "Further Studies on Leydig Cell Function in Old Age," The Journal of Clinical Endocrinology \& Metabolism, Vol. 39, No. 1, 1974, pp. 40-45. doi:10.1210/jcem-39-1-40

[30] H. W. Baker, et al., "Changes in the Pituitary-Testicular System with Age," Clinical Endocrinology, Vol. 5, No. 4, 1976, pp. 349-372. doi:10.1111/j.1365-2265.1976.tb01964.x

[31] K. M. Pirke and P. P. Doerr, "Age Related Changes in Free Plasma Testosterone, Dihydrotestosterone and Oestradiol," Acta Endocrinologica (Copenhagen), Vol. 80, No. 1, 1975, pp. 171-178.

[32] F. E. Purifoy, L. H. Koopmans and D. M. Mayes, "Age Differences in Serum Androgen Levels in Normal Adult Males," Human Biology, Vol. 53, No. 4, 1981, pp. 499511.

[33] W. J. Bremner, M. V. Vitiello and P. P. N. Prinz, "Loss of Circadian Rhythmicity in Blood Testosterone Levels with Aging in Normal Men," The Journal of Clinical Endocrinology \& Metabolism, Vol. 56, No. 6, 1983, pp. 12781281. doi:10.1210/jcem-56-6-1278
[34] J. S. Tenover, et al., "The Effects of Aging in Normal Men on Bioavailable Testosterone and Luteinizing Hormone Secretion: Response to Clomiphene Citrate," The Journal of Clinical Endocrinology \& Metabolism, Vol. 65, No. 6, 1987, pp. 1118-1126. doi:10.1210/jcem-65-6-1118

[35] A. Gray, et al., “An Examination of Research Design Effects on the Association of Testosterone and Male Aging: Results of a Meta-Analysis," Journal of Clinical Epidemiology, Vol. 44, No. 7, 1991, pp. 671-684. doi:10.1016/0895-4356(91)90028-8

[36] R. L. Ferrini and E. Barrett-Connor, "Sex Hormones and Age: A Cross-Sectional Study of Testosterone and Estradiol and Their Bioavailable Fractions in CommunityDwelling Men," American Journal of Epidemiology, Vol. 147, No. 8, 1998, pp. 750-754. doi:10.1093/oxfordjournals.aje.a009519

[37] M. W. Elmlinger, et al., "Reference Intervals for Testosterone, Androstenedione and SHBG Levels in Healthy Females and Males from Birth until Old Age," Clinical Laboratory, Vol. 51, No. 11-12, 2005, pp. 625-632.

[38] S. M. Harman and P. P. D. Tsitouras, "Reproductive Hormones in Aging Men. I. Measurement of Sex Steroids, Basal Luteinizing Hormone, and Leydig Cell Response to Human Chorionic Gonadotropin," The Journal of Clinical Endocrinology \& Metabolism, Vol. 51, No. 1, 1980, pp. 35-40. doi:10.1210/jcem-51-1-35

[39] E. Nieschlag, et al., "Reproductive Functions in Young Fathers and Grandfathers," The Journal of Clinical Endocrinology \& Metabolism, Vol. 55, No. 4, 1982, pp. 676-681. doi:10.1210/jcem-55-4-676

[40] A. Vermeulen, "Androgen Replacement Therapy in the Aging Male-A Critical Evaluation," The Journal of Clinical Endocrinology \& Metabolism, Vol. 86, No. 6, 2001, pp. 2380-2390. doi:10.1210/jc.86.6.2380

[41] J. E. Morley, et al., "Longitudinal Changes in Testosterone, Luteinizing Hormone, and Follicle-Stimulating Hormone in Healthy Older Men," Metabolism, Vol. 46, No. 4, 1997, pp. 410-413. doi:10.1016/S0026-0495(97)90057-3

[42] D. S. Ooi, et al., "Establishing Reference Intervals for DPC's Free Testosterone Radioimmunoassay," Clinical Biochemistry, Vol. 31, No. 1, 1998, pp. 15-21. doi:10.1016/S0009-9120(97)00143-4

[43] H. N. Bui, et al., "Serum Testosterone Levels Measured by Isotope Dilution-Liquid Chromatography-Tandem Mass Spectrometry in Postmenopausal Women versus Those in Women Who Underwent Bilateral Oophorectomy," Annals of Clinical Biochemistry, Vol. 47, No. 3, 2010, pp. 248-252. doi:10.1258/acb.2010.009171 